\title{
Monitoring asthma in childhood: lung function, bronchial responsiveness and inflammation
}

\author{
Alexander Moeller ${ }^{1}$, Kai-Hakon Carlsen ${ }^{2}$, Peter D. Sly ${ }^{3}$, Eugenio Baraldi ${ }^{4}$, \\ Giorgio Piacentini ${ }^{5}$, lan Pavord ${ }^{6}$, Christiane Lex $^{7}$ and Sejal Saglani ${ }^{8}$ on behalf of \\ the ERS Task Force Monitoring Asthma in Children ${ }^{9}$
}

\begin{abstract}
Affiliations: 'Division of Respiratory Medicine, University Children's Hospital Zurich, Zurich, Switzerland. ${ }^{2}$ Dept of Paediatrics, Women and Children's Division, University of Oslo and Oslo University Hospital, Oslo, Norway. ${ }^{3}$ Queensland Children's Medical Research Institute, The University of Queensland, Brisbane, Australia. “Women's and Children's Health Department, Unit of Respiratory Medicine and Allergy, University of Padova, Padova, Italy. ${ }^{5}$ Paediatric Section, Dept of Life and Reproduction Sciences, University of Verona, Verona, Italy. ${ }^{6}$ Dept of Respiratory Medicine, University of Oxford, NDM Research Building, Oxford, UK. ${ }^{7}$ Dept of Paediatric Cardiology and Intensive Care Medicine, Division of Paediatric Respiratory Medicine, University Hospital Goettingen, Goettingen, Germany. ${ }^{8}$ Leukocyte Biology and Respiratory Paediatrics, National Heart and Lung Institute, Imperial College London, London, UK. ${ }^{9} \mathrm{~A}$ full list of the ERS Task Force Monitoring Asthma in Children members and their affiliations can be found in the acknowledgements section.
\end{abstract}

Correspondence: Alexander Moeller, Division of Respiratory Medicine, University Children's Hospital Zurich, Zurich, Switzerland. E-mail: Alexander.Moellerakispi.uzh.ch

ABSTRACT This review focuses on the methods available for measuring reversible airways obstruction, bronchial hyperresponsiveness (BHR) and inflammation as hallmarks of asthma, and their role in monitoring children with asthma. Persistent bronchial obstruction may occur in asymptomatic children and is considered a risk factor for severe asthma episodes and is associated with poor asthma outcome. Annual measurement of forced expiratory volume in $1 \mathrm{~s}$ using office based spirometry is considered useful. Other lung function measurements including the assessment of BHR may be reserved for children with possible exercise limitations, poor symptom perception and those not responding to their current treatment or with atypical asthma symptoms, and performed on a higher specialty level. To date, for most methods of measuring lung function there are no proper randomised controlled or large longitudinal studies available to establish their role in asthma management in children.

Noninvasive biomarkers for monitoring inflammation in children are available, for example the measurement of exhaled nitric oxide fraction, and the assessment of induced sputum cytology or inflammatory mediators in the exhaled breath condensate. However, their role and usefulness in routine clinical practice to monitor and guide therapy remains unclear, and therefore, their use should be reserved for selected cases.

@ERSpublications

Review on the role of lung function, measurement of BHR and airway inflammation in monitoring of children with asthma http://ow.ly/KbHju

This is a supporting document of the ERS Task Force Monitoring Asthma in Children published in the European Respiratory Journal: Pijnenburg MW, Baraldi E, Brand PLP, et al. Monitoring asthma in children. Eur Respir J 2015; 45: 906-925.

Received: May 142014 | Accepted after revision: July 142014

Conflict of interest: Disclosures can be found alongside the online version of this article at err.ersjournals.com

Provenance: Submitted article, peer reviewed.

Copyright OERS 2015. ERR articles are open access and distributed under the terms of the Creative Commons Attribution Non-Commercial Licence 4.0. 


\section{Introduction}

Current guidelines recommend tailoring of asthma management according to disease control, which is generally defined by symptoms and, to a lesser extent, lung function and markers of airway inflammation. Recently, a European Respiratory Society (ERS) Task Force on Monitoring Asthma in Childhood was published [1]. As reversible airways obstruction, bronchial hyperresponsiveness (BHR) and chronic airways inflammation are hallmarks of asthma, this review focuses on available methods for and the usefulness of measuring lung function, bronchial responsiveness and inflammation when monitoring children with asthma.

Three other articles in this issue of the European Respiratory Review will address general considerations for monitoring asthma in children, monitoring symptoms, exacerbations and quality of life, and management-related issues [2-4].

\section{Lung function}

In children with asthma periodic objective assessment of pulmonary function is necessary to optimise management and ensure that therapeutic goals are being achieved. Significant bronchial obstruction may be present in asymptomatic asthmatic children and it has been shown that children with chronic airway obstruction are less likely to perceive dyspnoea compared with children with acute obstruction $[5,6]$. Children with poor perception of bronchial obstruction may be at higher risk of developing severe asthma episodes and reduced lung function is associated with poor asthma outcomes [7]. Therefore, regular assessment of lung function seems logical in monitoring of children with asthma. However, only $20-40 \%$ of primary care providers use lung function measurements in asymptomatic asthmatic patients and up to $59 \%$ of paediatricians never perform lung function tests [8-11].

\section{Maximal flow-volume curves}

Maximal expiratory flow-volume curves are considered the gold standard for the assessment of lung function in children with asthma. Regular assessment of pre- and post-bronchodilator forced expiratory volume in $1 \mathrm{~s}(\mathrm{FEV} 1)$ might help to identify children at risk for developing a progressive decline in airflow. Epidemiological studies have consistently shown a tracking of FEV1 and FEV1/forced vital capacity (FVC) ratio from childhood to adulthood $[12,13]$. On a shorter timescale, FEV1 has been shown to be an independent predictor of asthma exacerbations: asthmatic children with a baseline $\mathrm{FEV} 1<60 \%$ predicted have a doubled risk for asthma exacerbations in the subsequent year as compared with children with an $\mathrm{FEV}_{1}>80 \%$ predicted [14]. FEV 1 is considered important in defining asthma severity $[15,16]$. However, many, if not most, school children have an FEV1 $>80 \%$ predicted, hence within the accepted normal range independent of their asthma severity when defined on the basis of symptoms $[12,13]$. This indicates that the cut-off values may not adequately stratify asthmatic children [12]. Regular spirometry every 1-2 years has been recommended for children with asthma who are $\geqslant 5$ years of age by the National Asthma Education and Prevention Program (NAEPP) guidelines [16].

In children younger than 7 years of age, FEV1 may not be sensitive and may have a different physiological meaning as compared with older children [17]. However, there is insufficient data on the value of parameters of more peripheral airways, such as the forced expiratory flow at 50\% of FVC (FEF50\%) and/or forced expiratory flow at 25-75\% FVC (FEF25-75\%), in the monitoring of asthma in children. A large, retrospective cross-sectional analysis of the mean FEV1/FVC ratios from 4-18 years of age demonstrated a steep and consistent decline with increasing age in asthmatic children suggesting the $\mathrm{FEV} 1 / \mathrm{FVC}$ ratios provide greater sensitivity in childhood asthma compared with FEV1 [18].

In general, both FEV1 and the FEV1/FVC ratio correlate poorly with symptom-based severity in children, which may indicate that asthma management relying on reported symptoms only may be insufficient [ 19 , 20]. To date, there is no randomised controlled trial comparing monitoring of symptoms only to monitoring of symptoms plus FEV1 in asthmatic children.

While single FEV1 measurements may not reflect the inherent variability of the disease, home measurements using small, electronic hand-held devices may allow day-to-day monitoring of lung function. Data on the added value of regular home lung function measurement are conflicting. FEV 1 values obtained by home spirometry over a period of 8 weeks were significantly lower on days with asthma symptoms compared with symptom free days; however, the distribution of FEV 1 values showed complete overlap between symptomatic and asymptomatic days in individual patients [21]. The clinical value of home FEV1 measurements was reduced by a steady reduction in compliance and in the validity of the data over the study period, with wide individual differences [22]. Manoeuvre quality was influenced by age, treatment and region, and was lower in children with $\mathrm{FEV}_{1}<80 \%$ predicted [23]. BROUwER et al. [21] showed very high variability of FEV1 values over a 3-month period in asthmatic children with a poor concordance to other indices of disease activity. 
In summary, in children with asthma $>5$ years of age the evidence indicates that it is useful to perform office based spirometry at least annually, and more frequent assessments may be indicated depending on the clinical course and the patient's asthma severity. In patients in whom symptom-guided treatment is difficult home spirometry might be useful, but should preferably be limited to a relatively short period of observation. In children with severe asthma daily telemonitoring of $\mathrm{FEV}_{1}$ for 1 year did not reduce exacerbation rates [24].

There is a need for proper randomised controlled studies to establish the role of regular spirometry in asthma management in children. Studies should investigate the minimal or optimal frequency for the assessment of flow-volume curves. The value of the measurement of peripheral airflow obstruction, i.e. FEF50\% and/or $\mathrm{FEF} 25-75 \%$, needs to be established as these parameters are likely to reflect the pathophysiological processes in early asthma.

\section{Reversibility testing}

The response to bronchodilators demonstrating reversibility or airway obstruction is considered a key feature of asthma and therefore consistent with the diagnosis of asthma. The American Thoracic Society (ATS)/ERS recommendations define a significant bronchodilator response (BDR) as an increase in FEV $1 \geqslant 12 \%$ and/or $\geqslant 200 \mathrm{~mL}$ [25]. Children with a persistent BDR are at greater risk of developing a progressive decline in lung function, and have higher healthcare utilisation, lower asthma control and a more frequent need for oral steroid bursts. However, a persistent BDR may also be associated with poor treatment compliance or poor inhaler technique $[26,27]$. The presence of a BDR in asthmatic children is correlated to measures of airway inflammation, such as the exhaled nitric oxide fraction $(\mathrm{FeNO})$, and is predictive for a positive response to inhaled corticosteroids (ICSs) [28-30]. BDR tends to decrease over time indicating airway remodelling [31].

Based on the above, assessment of BDR in asthma monitoring is useful at a high specialty level. As there are variable influences on BDR, it is pertinent that the BDR test is performed as recommended [25]. In children with asthma with reduced FEV1 and loss of BDR (reduced post-BDR lung function) it is useful to consider further investigations and follow-up in specialist care.

A properly conducted trial using BDR to alter treatment is needed to further establish the usefulness of regular BDR measurement in clinical practice. It is still unclear which intervention should be undertaken in asthmatic children with a loss of BDR. Longitudinal or large cross-sectional studies should be carried out to assess age-specific response rates.

\section{Measurement of peak flow}

Regular monitoring of peak expiratory flow (PEF) is used widely in the management of patients with asthma as this is a simple and inexpensive method. Measurements of PEF on a day-to-day basis may allow monitoring of the variable airway obstruction, which is considered one of the key features of asthma and the variability in PEF may be predictive of exacerbations $[16,32]$. The mean day-to-day variability of peak flow in healthy children is between $6.2 \%$ and $8.2 \%$, with a 95th percentile of $12.3-31 \%$ [33, 34]. PEF has been shown to correlate with $\mathrm{FEV}$, but this correlation worsens in asthmatic patients with airflow limitation [35]. In a study in 40 asthmatic children the percentage of correct entries in a PEF diary was only $56 \%$ during the first week and declined to $<50 \%$ over the subsequent 4 weeks, with up to $50 \%$ of entries being invented or falsified [36].

Several studies have assessed the added value of daily PEF measurements to asthma management driven by symptom recognition in asthmatic children. One study found that patients who used PEF to guide therapy when symptomatic had a lower asthma severity score, fewer symptom days and less healthcare utilisation than children who either used PEF daily or evaluated subjective symptoms alone [37]. In an uncontrolled study, in 77 asthmatic children, daily PEF in combination with comprehensive asthma education resulted in a reduction in the number of asthma episodes, medical and emergency department visits, and missed school days [38]. Two randomised controlled studies did not show a benefit of PEF guided treatment compared with management based on symptoms alone, and addition of PEF did not enhance self-management even during acute exacerbations [28, 39]. Therefore, routine PEF measurements are not useful to monitor asthma in children.

\section{Measurement of airway resistance}

Interrupter resistance (Rint), impulse oscillometry (IOS) and the forced oscillation technique (FOT) assess respiratory resistance as an indirect measure of airway obstruction [40]. As these techniques can be carried out relatively independently of active collaboration they are suitable for preschool children [32, 41, 42]. While data on reference values are limited, these methods are reproducible and useful in the assessment of the BDR and bronchial responsiveness [42-48]. The cut-off values to detect significant differences between measurements are, however, variable [49, 50]. Longitudinal assessment of Rint did not improve the 
prediction of asthma symptoms until the age of 8 years [51]. IOS was compared with spirometry to assess the long-term effects of three controller regimens in children with persistent asthma. Whereas spirometric measures best reflected differences in controller therapy in the first 12 weeks of treatment, IOS was superior from 12 to 48 weeks [52]. By contrast to FEV1, increased IOS indices were predictive of the loss of asthma control and the area under the curve of baseline $R 5-20 \mathrm{~Hz}$ was 0.91 in the receiver operating characteristic analysis for the prediction of asthma control status after 8-12 weeks in a recent study in asthmatic children aged $7-17$ years [53].

Despite Rint, IOS or FOT measurements having some potential as monitoring tools in preschool asthmatics, to date, there are no longitudinal studies confirming their usefulness.

\section{Body plethysmography}

While in the majority of well-controlled asthmatic children flow-volume curves are sufficient for the monitoring of the disease, body plethysmographic measurements of lung volumes (i.e. air trapping) and compression-free forced expiratory flow-volume curves by use of "chest flow" from body plethysmography may be of interest in the management of difficult and severe asthma [54]. Asthmatic children with lung hyperinflation, defined as a residual volume of $>120 \%$ predicted, had more daytime asthma symptoms and lower body weight and body mass index, and $49 \%$ of children with airflow obstruction (FEV1/FVC $<80 \%$ ) showed significant hyperinflation [55]. In a large study, including 2193 asthmatic children, specific airway resistance was more strongly related to $\mathrm{FEF}_{50} \%$ than to $\mathrm{FEV}_{1}$, suggesting that specific airway resistance may reflect early airway obstruction in children [56]. Specific airway resistance measured at preschool age correlated with subsequent FEF50\%; therefore, predicting subsequent mild airflow limitation. In obese asthmatic children specific airway resistance measured by body plethysmography can be helpful in differentiating lung function changes due to asthma (elevated specific airway resistance) from those due to obesity (normal specific airway resistance) [57]. To date, there are no randomised controlled studies showing that body plethysmography is useful in routine monitoring of asthma in children.

Interventional studies may establish the additional value of body plethysmographic parameters in altering asthma treatment. It is still unclear which body plethysmographic values may predict short- and long-term outcomes of asthma in children. In addition, the value of helium dilution spirometry needs to be assessed.

\section{Multiple-breath gas washout techniques (lung clearance index)}

The lung clearance index (LCI), derived from multiple-breath inert gas washout, measures overall ventilation inhomogeneity. The advantages of LCI measurements are the narrow normal range and its independence of age [58]. LCI has been shown to be a sensitive marker of early airway disease in children with asthma and, in particular, in children with cystic fibrosis [59]. Scond (an index of conductive ventilation inhomogeneity) is based on the contribution to phase III slope from differences in ventilation distribution occurring in the conducting airway zone. A recent study in allergic asthmatic children found elevated Scond, and a close correlation between Scond and increased levels of FeNO and the presence of BHR [60]. In asthmatic school children baseline LCI was significantly higher when compared with healthy age-matched controls indicating greater overall ventilation heterogeneity [61].

As appropriate studies are lacking, to date, there is no role for multiple-breath washout techniques in the routine monitoring of children with asthma. The role of LCI in measuring early airway disease in children with asthma requires further exploration. As there is now commercially available equipment for nitrogen washout and for $\mathrm{SF}_{6}$ washout, future studies should aim to assess early asthma specific changes longitudinally in preschool and school aged children. In addition, treatment responses and predictors of the disease course should be a focus for future research.

\section{Infant lung function}

Different methods have been used to assess lung function in wheezy infants including the analysis of tidal flow-volume breathing loops, forced expirations from either normal inspiration (rapid thoracic compression technique) or from total lung capacity (raised volume rapid thoracic compression technique) or body plethysmography [62-67]. Infant lung function testing has been used to assess phenotypes in infants with wheezing and to develop prediction models for persistent asthma [68]. Reduced lung function and/or BHR in infancy were associated with persistent wheezing phenotypes, and with reduced lung function and asthma at school age $[62,67-70]$. In addition, reduced lung function was predictive for wheezy symptoms in the following years [61, 71-73]. Reduced lung function in infancy was associated with respiratory morbidity and treatment needs at preschool age [65]. Some studies showed improvement of lung function, such as forced expiratory volume in $0.5 \mathrm{~s}$, in infants with recurrent wheezing after ICS treatment or oral treatment with montelukast, whereas others did not show significant changes $[63,64,74,75]$. 
To date, there is no role for infant lung function testing in the clinical monitoring of wheezing infants. Future research should focus on methods for infant lung function testing that allow repeated measurements in unsedated children.

\section{Bronchial hyperresponsiveness}

One major characteristic of asthma is the variability in bronchial tone in a response to a variety of different stimuli.

BHR may be assessed by bronchial provocation tests and can be used both in research and as a means of monitoring the severity of asthma. Bronchial provocation tests may be performed with different chemical substances, such as histamine or methacholine (both of which are considered nonspecific direct bronchoprovocation tests), or by inhaling allergens (specific direct bronchoprovocation tests) as well as by using variety of stimuli such as physical exercise, inhaled cold air and hyperventilation with dry air (all of which are indirect bronchial provocation tests) [76-83].

Determination the provocative concentration or dose causing a $20 \%$ reduction in FEV1 is used for bronchoprovocation tests with methacholine, histamine and AMP, and may be used for allergen bronchoprovocation tests $[77,84]$. A bronchoprovocation test with inhaled mannitol was recently developed and launched commercially in a test involving inhaling cumulative doses of mannitol through a powder inhaler. In this test a $15 \%$ reduction in FEV1 is used as cut-off [83]. Although mannitol provocation seems safe and feasible, even in young children, the specific role of mannitol provocation in exploring BHR in asthmatic children needs further study [85]. Exercise testing is the most important measure of indirect bronchial responsiveness. A reduction in FEV1 of at least $10 \%$ is taken as a sign of exercise-induced bronchoconstriction. A correctly performed exercise test gives information about the presence of exercise-induced bronchoconstriction as well as the motor development and fitness of the child. In all international guidelines on treating asthma in childhood mastering exercise-induced asthma is seen as a major objective in the treatment of asthma, with the exercise test as an important tool. The standardisation of the exercise test is important with regard to environmental factors such as temperature, humidity of the inhaled air and exercise load [86-88]. Running is the preferred exercise, and is most easily standardised using a treadmill for a test of 6-8 min duration, reaching and maintaining an exercise load of $90-95 \%$ of the calculated maximum for the last $4 \mathrm{~min}$ of the test [88-90]. The sensitivity of the exercise test can be increased by inhaling cold or dry air during exercise [91]. The exercise test can be used for the diagnosis of exercise-induced bronchoconstriction, but also to assess the protective effect of asthma drugs against exercise-induced bronchoconstriction.

With the diagnosis of asthma in mind, direct BHR is seen as the most sensitive measure of bronchial asthma, whereas indirect measures of BHR are considered to be more specific and less sensitive [77]. Compared with exercise testing, methacholine bronchoprovocation tests are more sensitive, but markedly less specific, to discriminate between asthma and other chronic lung diseases. When cold air inhalation was added to the exercise test sensitivity comparable to methacholine test was reached, while maintaining the sensitivity [91]. Indirect bronchoprovocation tests are rapidly influenced by treatment with inhaled steroids with the first effects already appearing after 1 week, whereas methacholine bronchoprovocation tests required several months of inhaled steroid treatment to show an effect [92, 93]. Treatment adjustment in children with moderate asthma, based on methacholine bronchoprovocation tests, did not result in a reduction in the percentage of symptom-free days but led to higher pre-bronchodilator FEV1 as compared with a strategy based on symptom score only [94].

Methacholine bronchoprovocation tests may have a role in predicting later active asthma, as shown in a birth cohort study between 10 and 16 years of age [95]. In general practice moderate and severe BHR to methacholine could not be predicted by routinely available clinical and environmental information in the majority of children [96]. Similarly, several studies revealed poor correlation between reported exercise-related respiratory symptoms and the results of specific exercise testing [97].

In summary, the evidence shows that routine assessment of BHR is not useful in children with asthma; however, there may be a place for BHR assessments in children with possible exercise limitations, poor symptom perception and those not responding to their current treatment or with atypical asthma symptoms. The role of indirect provocation agents such as mannitol and AMP in asthma monitoring needs attention in longitudinal studies.

\section{Markers of inflammation}

Noninvasive biomarkers for monitoring inflammation in children are available, but their role and usefulness in routine clinical practice to monitor and guide therapy is unclear. The selection of an 
appropriate inflammatory marker must take several factors into consideration including safety, reproducibility, repeatability, sensitivity to treatment, and overall clinical utility.

\section{Exhaled nitric oxide fraction}

The best studied biomarker in asthma is FeNO, which has been reported to reflect both airway and tissue eosinophilia. FeNO can be measured noninvasively, and is an extremely attractive technique for use in children. The measurement of FeNO has been standardised for clinical use in a joint guideline from the ATS and ERS [98]. The conventional chemiluminescence FeNO analyser, the hand-held device and offline FeNO measurements have been shown to produce similar results in children older than 5 years of age with a success rate of $>70 \%$ and with an overall coefficient of repeatability of around 1.6-3.2 ppb [99-104]. A low FeNO $(<20 \mathrm{ppb})$ in children with asthma not treated with ICSs indicates that eosinophilic inflammation and responsiveness to corticosteroids are less likely. FeNO values between 20 and $35 \mathrm{ppb}$ are intermediate and should be interpreted cautiously, while high values above $35 \mathrm{ppb}$ are indicative of eosinophilic inflammation $[105,106]$. Currently, there is no international consensus on using age- and height-adjusted normal values or adjusting for atopy $[105,107]$. There are many additional factors associated with minor changes in FeNO, such as treatment compliance, diet, allergen exposure, active and passive tobacco smoke exposure, and diurnal variability. Therefore, small changes in FeNO (i.e. $<10 \mathrm{ppb}$ ) may be clinically irrelevant.

A FeNO level of $>49 \mathrm{ppb} 4$ weeks after stopping ICSs was found to predict asthma relapse with a sensitivity of $71 \%$ and specificity of $93 \%$ [108]. In another study, FeNO and the percentage of sputum eosinophils were both significant predictors of failed ICS reduction in clinically stable children with mild-to-moderate asthma [109]. Two other studies failed to show any significant utility of FeNO in predicting exacerbations in children undergoing ICS tapering $[110,111]$.

Most studies investigating the utility of FeNO to guide treatment have used a combination of FeNO with other measures of asthma control, rather than FeNO alone. FeNO-guided treatment in children with asthma did not show a difference between the groups in terms of the cumulative dose of ICSs (sum of doses at each visit), but there was a significant decrease in BHR in the FeNO group [112]. In another study FeNO-guided treatment resulted in higher expiratory flow at 50\% of the predicted FVC compared with the symptom-guided group [113]. There were no significant differences in any of the other secondary outcomes: FeNO, FEV1, number of exacerbations, symptom control, or use of short acting $\beta$-agonists [113]. In the study by SzEFLER et al. [114] no differences were shown between groups looking at days with asthma symptoms, days of school missed, asthma control test score, courses of oral corticosteroids, FEV1, or FeNO levels. The dose of ICS was nonsignificantly higher in the FeNO group. Daily measures of FeNO were compared with symptoms to guide treatment changes in children [115]. Both treatment strategies resulted in a significant improvement in symptom-free days and quality of life, and a reduction in ICS dose, but neither approach was superior. Studies which have incorporated FeNO into management algorithms have used many different protocols, not only in terms of the frequency of measurements but also the inclusion of other indices of asthma control. The results were variable with only some showing significant results, but the outcome measures were not consistent across studies.

An increasing amount of information is available relating to the utility of FeNO assessments in younger children, and recently, normative data for FeNO in infants has been reported [116]. In children with preschool wheeze, levels of FeNO were higher in those with current symptoms or atopy compared with controls [117, 118]. Although anti-inflammatory therapy has been shown to reduce FeNO in wheezy preschool children, there are no published data on its utility in monitoring control, adjusting therapy or in predicting exacerbations $[63,64,119-121]$. Some data imply that elevated FeNO in preschool children is associated with later asthma [122-124]. Elevated FeNO predicted decline in lung function in infants with recurrent wheezing, and the risk of future wheezing in both healthy neonates and wheezy infants $[125,126]$. FeNO does not seem to correlate well with lung function in early childhood, but it does correlate with BHR $[127,128]$.

Taken together, based on current evidence FeNO is not useful for routine monitoring of children with asthma, although most task force members use FeNO in children with difficult or uncontrolled asthma especially in specialist centres. Clinical trials that assess the utility of FeNO in adjusting treatment or in predicting exacerbations in preschool children have not been performed. It is still unclear what represents a significant change in FeNO in a longitudinal setting.

\section{Sputum analysis}

Analysis of induced sputum cytology is a partially noninvasive tool that allows assessment of inflammatory cells, such as eosinophils and neutrophils, as well as inflammatory mediators in supernatants.

Performance of sputum induction and sample processing have been standardised for use in children and is well described by ERS recommendations [129]. Sputum induction has been shown to be safe in asthmatic 
children, regardless of disease severity, and feasibility is $80-85 \%$ in children between 6 and 17 years of age $[130,131]$. The methodology has not yet been standardised in preschool children.

The percentage of eosinophils is the most frequently used marker in clinical studies. In a prospective open label clinical study in 40 children with mild-to-moderate asthma reducing ICS was successful in all children who had no eosinophils in induced sputum before the reduction was undertaken. and induced sputum eosinophils $\geqslant 2 \%$ had a sensitivity of $63.6 \%$ and a specificity of $75.7 \%$ for predicting failed reduction [109]. Eosinophils in induced sputum were significantly higher in children with stable asthma who experienced exacerbations on reducing ICSs [132]. In severe asthmatic children a tailored intervention based on sputum eosinophils did not significantly reduce overall asthma exacerbations or improve asthma control when compared with conventional management based on clinical symptoms and lung function [130]. In contrast to adults, children with difficult asthma responded to high-dose corticosteroids even in the absence of sputum eosinophilia [133]. Therefore, detection of a non-eosinophilic sputum phenotype in isolation does not mean clinical ineffectiveness of corticosteroids. Longitudinal assessments of sputum eosinophils in children with severe and mild-to-moderate asthma suggest inflammatory phenotypes are not stable over time, even without any intervening changes to therapy or in the clinical disease [130].

For now, the evidence suggests that sputum induction is not useful to monitor asthma in routine clinical practice. However, for specific patients in specialised tertiary centres sputum eosinophils may be helpful when making difficult treatment decisions.

\section{Exhaled breath condensate}

Exhaled breath condensate (EBC) analysis has become an increasingly used and promising method in research, as a wide number of inflammatory mediators can be measured in EBC. It is a simple, well tolerated and safe method, even in children with severe asthma, and is feasible in $100 \%$ of children over 4 years of age [134]. Children with asthma can be discriminated from healthy controls with EBC analysis $[135,136]$. However, although the method is simple, it can be influenced by a number of technical issues, which can affect the final results. Despite the publication of a joint ATS/ERS task force document on methodological considerations, many questions are not yet properly resolved [137]. EBC collection in preschool children is of particular interest as the measurement of selected exhaled markers may allow distinction between different phenotypes of wheezing [137-139]. However, the collection procedure in children younger than 4 years of age may be more difficult due to the lower level of cooperation and smaller amounts of EBC. Nevertheless, its feasibility in this age group has been demonstrated using customised devices [120,140].

Assessment of markers of oxidative stress in the airway makes it possible to monitor otherwise neglected indicators of disease control. 8-isoprostane levels in EBC distinguished children with stable and unstable asthma, independent of treatment with ICS [141]. Hydrogen peroxide was related to asthma control in a group of asthmatics above 12 years of age [142]. In a large study, FeNO, 8-isoprostane, interferon- $\gamma$ and interleukin-4 were related to asthma control, and FeNO, 8-isoprostane, nitrate and nitrite in EBC better indicated the degree of asthma severity [143]. More recently, KosTiKAs et al. [144] focused on EBC pH as a potential indicator of asthma control in a group of nearly 250 asthmatics grouped according to their level of control as defined by Global Initiative for Asthma guidelines [145]. EBC pH is known to be low during exacerbations, with normalisation after adequate treatment, and is related to disease severity [146, 147]. The measurement of EBC $\mathrm{pH}$ may be the most easily achievable measurement from EBC in a clinical setting since it can be performed onsite with relatively simple methods. Due to methodological issues and the lack of clinical trials of EBC in the monitoring of asthma, to date, EBC does not play a role in the monitoring of asthma in children.

\section{Conclusions}

The lack of proper randomised controlled or large longitudinal studies makes it difficult to establish the role of measuring lung function, BHR and airways inflammation in asthma management in children.

The regular measurement of FEV1 using office based spirometry is considered useful. However, other lung function measurements including the assessment of BHR and airways inflammation may be reserved for selected children with exercise limitations, poor symptom perception or with atypical asthma symptoms and difficult or uncontrolled asthma, and performed on a higher specialty level.

\section{Acknowledgements}

The Task Force members and their affiliations are as follows. Alexander Moeller: Division of Respiratory Medicine, University Children's Hospital Zurich, Zurich, Switzerland; Kai-Hakon Carlsen: Dept of Paediatrics, Women and Children's Division, University of Oslo and Oslo University Hospital, Oslo, Norway; Peter D. Sly: Queensland Children's Medical Research Institute, The University of Queensland, Brisbane, Australia; Eugenio Baraldi: Women's and Children's Health Department, Unit of Respiratory Medicine and Allergy, University of Padova, Padova, Italy; 
Giorgio Piacentini: Paediatric Section, Dept of Life and Reproduction Sciences, University of Verona, Verona, Italy; Ian Pavord: Dept of Respiratory Medicine, University of Oxford, NDM Research Building, Oxford, UK; Christiane Lex: Dept of Paediatric Cardiology and Intensive Care Medicine, Division of Paediatric Respiratory Medicine, University Hospital Goettingen, Goettingen, Germany; Sejal Saglani: Leukocyte Biology and Respiratory Paediatrics, National Heart and Lung Institute, Imperial College London, London, UK; Paul L.P. Brand: Dept Paediatrics/Princess Amalia Children's Centre, Isala Hospital, Zwolle, and UMCG Postgraduate School of Medicine, University Medical Centre and University of Groningen, Groningen, The Netherlands; Ernst Eber: Respiratory and Allergic Disease Division, Dept of Paediatrics and Adolescence Medicine, Medical University of Graz, Graz, Austria; Thomas Frischer: Dept Paediatrics and Paediatric Surgery, Wilhelminenspital, Vienna, Austria; Gunilla Hedlin: Dept of Women's and Children's health and Centre for Allergy Research, Karolinska Institutet and Astrid Lindgren Children's hospital, Stockholm, Sweden; Neeta Kulkarni: Leicestershire Partnership Trust and Dept of Infection, Immunity and Inflammation, University of Leicester, Leicester, UK; Karin C. Lødrup Carlsen: Dept of Paediatrics, Women and Children's Division, Oslo University Hospital, and Dept of Paediatrics, Faculty of Medicine, University of Oslo, Oslo, Norway; Mika J. Mäkelä: Skin and Allergy Hospital, Helsinki University Hospital, Helsinki, Finland; Eva Mantzouranis: Dept of Paediatrics, University Hospital of Heraklion, University of Crete, Heraklion, Greece; Mariëlle W. Pijnenburg: Dept Paediatrics/Paediatric Respiratory Medicine, Erasmus MC - Sophia Children's Hospital, Rotterdam, The Netherlands; David Price: Dept of Primary Care Respiratory Medicine, Academic Primary Care, Division of Applied Health Sciences, University of Aberdeen, Aberdeen,

UK; Bart L. Rottier: Dept of Pediatric Pulmonology and Allergology, GRIAC Research Institute, University Medical Center Groningen, University of Groningen, Groningen, The Netherlands; Stanley J. Szefler: Children's Hospital Colorado and University of Colorado Denver School of Medicine, Denver, CO, USA; Steve Turner: Dept Paediatrics, University of Aberdeen, Aberdeen, UK; Edwina Wooler: Royal Alexandra Children's Hospital, Brighton, UK.

\section{References}

Pijnenburg MW, Baraldi E, Brand PLP, et al. Monitoring asthma in children. Eur Respir J 2015; 45: 906-925. Lødrup Carlsen KC, Pijnenburg MW. Monitoring asthma in childhood. Eur Respir Rev 2015; 24: 178-186.

Brand PLP, Mäkelä MJ, Szefler SJ, et al. Monitoring asthma in childhood: symptoms, exacerbations and quality of life. Eur Respir Rev 2015; 24: 187-193.

4 Rottier BL, Eber E, Hedlin G, et al. Monitoring asthma in childhood: management-related issues. Eur Respir Rev 2015; 24: 194-203.

$5 \quad$ Rietveld S, Everaerd W. Perceptions of asthma by adolescents at home. Chest 2000; 117: 434-439.

6 Clough JB, Holgate ST. Episodes of respiratory morbidity in children with cough and wheeze. Am J Respir Crit Care Med 1994; 150: 48-53.

7 Bijl-Hofland ID, Cloosterman SG, Folgering HT, et al. Relation of the perception of airway obstruction to the severity of asthma. Thorax 1999; 54: 15-19.

8 Grant EN, Moy JN, Turner-Roan K, et al. Asthma care practices, perceptions, and beliefs of Chicago-area primary-care physicians. Chicago Asthma Surveillance Initiative Project Team. Chest 1999; 116: Suppl. 1, $145 \mathrm{~S}-154 \mathrm{~S}$

9 Finkelstein JA, Lozano P, Shulruff R, et al. Self-reported physician practices for children with asthma: are national guidelines followed? Pediatrics 2000; 106: Suppl., 886-896.

10 García-Marcos L, Castro-Rodríguez JA, Montaner AE, et al. The use of spirometers and peak flow meters in the diagnosis and management of asthma among Spanish pediatricians. Results from the TRAP study. Pediatr Allergy Immunol 2004; 15: 365-371.

11 Dombkowski KJ, Hassan F, Wasilevich EA, et al. Spirometry use among pediatric primary care physicians. Pediatrics 2010; 126: 682-687.

12 Liu AH. Biomarkers and childhood asthma: improving control today and tomorrow. Allergy Asthma Proc 2005; 26: $249-254$.

13 Sears MR, Greene JM, Willan AR, et al. A longitudinal, population-based, cohort study of childhood asthma followed to adulthood. $N$ Engl J Med 2003; 349: 1414-1422.

14 Fuhlbrigge AL, Kitch BT, Paltiel AD, et al. FEV1 is associated with risk of asthma attacks in a pediatric population. J Allergy Clin Immunol 2001; 107: 61-67.

15 National Asthma Education and Prevention Program. National Asthma Education and Prevention Program. Expert panel report: guidelines for the diagnosis and management of asthma update on selected topics - 2002. J Allergy Clin Immunol 2002; 110: Suppl., S141-S219.

16 National Asthma Education and Prevention Program. Expert panel report 3 (EPR-3): guidelines for the diagnosis and management of asthma - summary report 2007. J Allergy Clin Immunol 2007; 120: Suppl., S94-S138.

17 Vonk JM, Postma DS, Boezen HM, et al. Childhood factors associated with asthma remission after 30 year follow up. Thorax 2004; 59: 925-929.

18 Paull K, Covar R, Jain N, et al. Do NHLBI lung function criteria apply to children? A cross-sectional evaluation of childhood asthma at National Jewish Medical and Research Center, 1999-2002. Pediatr Pulmonol 2005; 39: 311-317.

19 Bacharier LB, Strunk RC, Mauger D, et al. Classifying asthma severity in children: mismatch between symptoms, medication use, and lung function. Am J Respir Crit Care Med 2004; 170: 426-432.

20 Sly PD, Landau LI, Weymouth R. Home recording of peak expiratory flow rates and perception of asthma. Am J Dis Child 1985; 139: 479-482.

21 Brouwer AF, Roorda RJ, Brand PL. Home spirometry and asthma severity in children. Eur Respir J 2006; 28 : 1131-1137.

22 Wensley DC, Silverman M. The quality of home spirometry in school children with asthma. Thorax 2001; 56: 183-185.

23 Thompson R, Delfino RJ, Tjoa T, et al. Evaluation of daily home spirometry for school children with asthma: new insights. Pediatr Pulmonol 2006; 41: 819-828.

24 Deschildre A, Béghin L, Salleron J, et al. Home telemonitoring (forced expiratory volume in $1 \mathrm{~s}$ ) in children with severe asthma does not reduce exacerbations. Eur Respir J 2012; 39: 290-296. 
Pellegrino R, Viegi G, Brusasco V, et al. Interpretative strategies for lung function tests. Eur Respir J 2005; 26 : 948-968.

Sharma S, Litonjua AA, Tantisira KG, et al. Clinical predictors and outcomes of consistent bronchodilator response in the childhood asthma management program. J Allergy Clin Immunol 2008; 122: 921-928.

Holt EW, Cook EF, Covar RA, et al. Identifying the components of asthma health status in children with mild to moderate asthma. J Allergy Clin Immunol 2008; 121: 1175-1180.

Tantisira KG, Fuhlbrigge AL, Tonascia J, et al. Bronchodilation and bronchoconstriction: predictors of future lung function in childhood asthma. J Allergy Clin Immunol 2006; 117: 1264-1271.

Covar RA, Szefler SJ, Martin RJ, et al. Relations between exhaled nitric oxide and measures of disease activity among children with mild-to-moderate asthma. J Pediatr 2003; 142: 469-475.

Strunk RC, Szefler SJ, Phillips BR, et al. Relationship of exhaled nitric oxide to clinical and inflammatory markers of persistent asthma in children. J Allergy Clin Immunol 2003; 112: 883-892.

Goleva E, Hauk PJ, Boguniewicz J, et al. Airway remodeling and lack of bronchodilator response in steroid-resistant asthma. J Allergy Clin Immunol 2007; 120: 1065-1072.

Thamrin C, Gangell CL, Udomittipong K, et al. Assessment of bronchodilator responsiveness in preschool children using forced oscillations. Thorax 2007; 62: 814-819. schoolchildren using home spirometry. Eur Respir J 2008; 32: 1262-1268. rates. Relationship to symptoms and respiratory disease. Am Rev Respir Dis 1991; 143: 323-330.

Brand PL, Roorda RJ. Usefulness of monitoring lung function in asthma. Arch Dis Child 2003; 88: 1021-1025. Kamps AW, Roorda RJ, Brand PL. Peak flow diaries in childhood asthma are unreliable. Thorax 2001; 56: 180-182. Yoos HL, Kitzman H, McMullen A, et al. Symptom monitoring in childhood asthma: a randomized clinical trial comparing peak expiratory flow rate with symptom monitoring. Ann Allergy Asthma Immunol 2002; 88: 283-291.

Burkhart PV, Rayens MK, Revelette WR, et al. Improved health outcomes with peak flow monitoring for children with asthma. J Asthma 2007; 44: 137-142.

Wensley D, Silverman M. Peak flow monitoring for guided self-management in childhood asthma: a randomized controlled trial. Am J Respir Crit Care 2004; 170: 606-612.

Mochizuki H, Hirai K, Tabata H. Forced oscillation technique and childhood asthma. Allergol Int 2012; 61: 373-383.

Goldman MD. Clinical application of forced oscillation. Pulm Pharmacol Ther 2001; 14: 341-350.

Klug B, Bisgaard H. Measurement of lung function in awake 2-4-year-old asthmatic children during methacholine challenge and acute asthma: a comparison of the impulse oscillation technique, the interrupter technique, and transcutaneous measurement of oxygen versus whole-body plethysmography. Pediatr Pulmonol 1996; 21: 290-300.

3 Komarow HD, Skinner J, Young M, et al. A study of the use of impulse oscillometry in the evaluation of children with asthma: analysis of lung parameters, order effect, and utility compared with spirometry. Pediatr Pulmonol 2012; 47: 18-26.

McKenzie SA, Chan E, Dundas I, et al. Airway resistance measured by the interrupter technique: normative data for 2-10 year olds of three ethnicities. Arch Dis Child 2002; 87: 248-251.

Merkus PJ, Mijnsbergen JY, Hop WC, et al. Interrupter resistance in preschool children: measurement characteristics and reference values. Am J Respir Crit Care Med 2001; 163: 1350-1355.

Boccaccino A, Peroni DG, Pietrobelli A, et al. Assessment of variable obstruction by forced expiratory volume in 1 second, forced oscillometry, and interrupter technique. Allergy Asthma Proc 2007; 28: 331-335.

Hall GL, Gangell C, Fukushima T, et al. Application of a shortened inhaled adenosine-5'-monophosphate challenge in young children using the forced oscillation technique. Chest 2009; 136: 184-189.

Wilson NM, Bridge P, Silverman M. Bronchial responsiveness and symptoms in 5-6 year old children: a comparison of a direct and indirect challenge. Thorax 1995; 50: 339-345.

9 Beydon N, M'Buila C, Bados A, et al. Interrupter resistance short-term repeatability and bronchodilator response in preschool children. Respir Med 2007; 101: 2482-2487.

Mele L, Sly PD, Calogero C, et al. Assessment and validation of bronchodilation using the interrupter technique in preschool children. Pediatr Pulmonol 2010; 45: 633-638.

Caudri D, Wijga AH, Hoekstra MO, et al. Prediction of asthma in symptomatic preschool children using exhaled nitric oxide, Rint and specific IgE. Thorax 2010; 65: 801-807.

Larsen GL, Morgan W, Heldt GP, et al. Impulse oscillometry versus spirometry in a long-term study of controller therapy for pediatric asthma. J Allergy Clin Immunol 2009; 123: 861-867.

Shi Y, Aledia AS, Galant SP, et al. Peripheral airway impairment measured by oscillometry predicts loss of asthma control in children. J Allergy Clin Immunol 2013; 131: 718-723.

Jenkins HA, Cherniack R, Szefler SJ, et al. A comparison of the clinical characteristics of children and adults with severe asthma. Chest 2003; 124: 1318-1324.

5 Labbe G, Merlin E, Kauffman C, et al. Interet de la mesure des volumes pulmonaires par plethysmographie corporelle dans le suivi de l'asthme de l'enfant [The role of lung volume measurements by plethysmography in the follow-up of asthma in children]. Rev Mal Respir 2010; 27: 42-48.

Mahut B, Trinquart L, Bokov P, et al. Relationships between specific airway resistance and forced expiratory flows in asthmatic children. PLoS One 2009; 4: e5270.

Mahut B, Beydon N, Delclaux C. Overweight is not a comorbidity factor during childhood asthma: the GrowthOb study. Eur Respir J 2012; 39: 1120-1126.

Aurora P, Kozlowska W, Stocks J. Gas mixing efficiency from birth to adulthood measured by multiple-breath washout. Respir Physiol Neurobiol 2005; 148: 125-139.

Gustafsson PM. Peripheral airway involvement in CF and asthma compared by inert gas washout. Pediatr Pulmonol 2007; 42: 168-176.

Keen C, Olin AC, Wennergren G, et al. Small airway function, exhaled NO and airway hyper-responsiveness in paediatric asthma. Respir Med 2011; 105: 1476-1484. 
61 Macleod KA, Horsley AR, Bell NJ, et al. Ventilation heterogeneity in children with well controlled asthma with normal spirometry indicates residual airways disease. Thorax 2009; 64: 33-37.

62 Turner SW, Young S, Goldblatt J, et al. Childhood asthma and increased airway responsiveness: a relationship that begins in infancy. Am J Respir Crit Care Med 2009; 179: 98-104.

63 Moeller A, Franklin P, Hall GL, et al. Inhaled fluticasone dipropionate decreases levels of nitric oxide in recurrenty wheezy infants. Pediatr Pulmonol 2004; 38: 250-255.

64 Straub DA, Moeller A, Minocchieri S, et al. The effect of montelukast on lung function and exhaled nitric oxide in infants with early childhood asthma. Eur Respir J 2005; 25: 289-294.

65 Pelkonen AS, Kotaniemi-Syriänen A, Malmström K, et al. Clinical findings associated with abnormal lung function in children aged 3-26 months with recurrent respiratory symptoms. Acta Paediatr 2010; 99: 1175-1179.

66 Young S, Arnott J, O'Keeffe PT, et al. The association between early life lung function and wheezing during the first 2 yrs of life. Eur Respir J 2000; 15: 151-157.

67 Håland G, Carlsen KC, Sandvik L, et al. Reduced lung function at birth and the risk of asthma at 10 years of age. N Engl J Med 2006; 355: 1682-1689.

68 Martinez FD, Wright AL, Taussig LM, et al. Asthma and wheezing in the first six years of life. The Group Health Medical Associates. N Engl J Med 1995; 332: 133-138.

69 Turner SW, Palmer LJ, Rye PJ, et al. Infants with flow limitation at 4 weeks: outcome at 6 and 11 years. Am J Respir Crit Care Med 2002; 165: 1294-1298.

70 Palmer LJ, Rye PJ, Gibson NA, et al. Airway responsiveness in early infancy predicts asthma, lung function, and respiratory symptoms by school age. Am J Respir Crit Care Med 2001; 163: 37-42.

71 Malmström K, Pelkonen AS, Malmberg LP, et al. Lung function, airway remodelling and inflammation in symptomatic infants: outcome at 3 years. Thorax 2011; 66: 157-162.

72 Murray CS, Pipis SD, McArdle EC, et al. Lung function at one month of age as a risk factor for infant respiratory symptoms in a high risk population. Thorax 2002; 57: 388-392.

73 Pike KC, Rose-Zerilli MJ, Osvald EC, et al. The relationship between infant lung function and the risk of wheeze in the preschool years. Pediatr Pulmonol 2011; 46: 75-82.

74 Mallol J, Aguirre V, Barrueto L, et al. Effect of inhaled fluticasone on lung function in infants with recurrent wheezing: a randomised controlled trial. Allergol Immunopathol (Madr) 2009; 37: 57-62.

75 Pelkonen AS, Malmström K, Sarna S, et al. The effect of montelukast on respiratory symptoms and lung function in wheezy infants. Eur Respir J 2013; 41: 664-670.

76 Aas K. Bronchial provocation tests in asthma. Arch Dis Child 1970; 45: 221-228.

77 Cockcroft DW, Killian DN, Mellon JJ, et al. Bronchial reactivity to inhaled histamine: a method and clinical survey. Clin Allergy 1977; 7: 235-243.

78 Hargreave FE, Ryan G, Thomson NC, et al. Bronchial responsiveness to histamine or methacholine in asthma: measurement and clinical significance. J Allergy Clin Immunol 1981; 68: 347-355.

79 Jones RS, Wharton MJ, Buston MH. The place of physical exercise and bronchodilator drugs in the assessment of the asthmatic child. Arch Dis Child 1963; 38: 539-545.

80 Zach MS, Polgar G. Cold air challenge of airway hyperreactivity in children: dose-response interrelation with a reaction plateau. J Allergy Clin Immunol 1987; 80: 9-17.

81 Rosenthal RR. Simplified eucapnic voluntary hyperventilation challenge. J Allergy Clin Immunol 1984; 73: 676-679.

82 Avital A, Springer C, Bar-Yishay E, et al. Adenosine, methacholine, and exercise challenges in children with asthma or paediatric chronic obstructive pulmonary disease. Thorax 1995; 50: 511-516.

83 Brannan JD, Anderson SD, Perry CP, et al. The safety and efficacy of inhaled dry powder mannitol as a bronchial provocation test for airway hyperresponsiveness: a phase 3 comparison study with hypertonic (4.5\%) saline. Respir Res 2005; 6: 144.

84 Yan K, Salome C, Woolcock AJ. Rapid method for measurement of bronchial responsiveness. Thorax 1983; 38: 760-765.

85 Alblooshi AS, Simpson SJ, Stick SM, et al. The safety and feasibility of the inhaled mannitol challenge test in young children. Eur Respir J 2013; 42: 1420-1423.

86 Stensrud T, Berntsen S, Carlsen KH. Exercise capacity and exercise-induced bronchoconstriction (EIB) in a cold environment. Respir Med 2007; 101: 1529-1536.

87 Stensrud T, Berntsen S, Carlsen KH. Humidity influences exercise capacity in subjects with exercise-induced bronchoconstriction (EIB). Respir Med 2006; 100: 1633-1641.

88 Carlsen KH, Engh G, Mørk M. Exercise-induced bronchoconstriction depends on exercise load. Respir Med 2000; 94: 750-755.

89 Anderson SD, Silverman M, Tai E, et al. Specificity of exercise in exercise-induced asthma. Br Med J 1971; 4: $814-815$.

90 Godfrey S, Silverman M, Anderson SD. The use of the treadmill for assessing exercise-induced asthma and the effect of varying the severity and duration of exercise. Pediatrics 1975; Suppl., 56: 893-898.

91 Carlsen KH, Engh G, Mørk M, et al. Cold air inhalation and exercise-induced bronchoconstriction in relationship to metacholine bronchial responsiveness: different patterns in asthmatic children and children with other chronic lung diseases. Respir Med 1998; 92: 308-315.

92 Henriksen JM, Dahl R. Effects of inhaled budesonide alone and in combination with low-dose terbutaline in children with exercise-induced asthma. Am Rev Respir Dis 1983; 128: 993-997.

93 van Essen-Zandvliet EE, Hughes MD, Waalkens HJ, et al. Effects of 22 months of treatment with inhaled corticosteroids and/or beta-2-agonists on lung function, airway responsiveness, and symptoms in children with asthma. The Dutch Chronic Non-specific Lung Disease Study Group. Am Rev Respir Dis 1992; 146: 547-554.

94 Nuijsink M, Hop WC, Sterk PJ, et al. Long-term asthma treatment guided by airway hyperresponsiveness in children: a randomised controlled trial. Eur Respir J 2007; 30: 457-466.

95 Riiser A, Hovland V, Carlsen KH, et al. Does bronchial hyperresponsiveness in childhood predict active asthma in adolescence? Am J Respir Crit Care Med 2012; 186: 493-500.

96 Hagmolen Of Ten Have W, van den Berg NJ, van der Palen J, et al. Severe airway hyperresponsiveness was not predictable with the use of current tools in asthmatic children in general practice. J Clin Epidemiol 2007; 60: $1052-1059$. 
De Baets F, Bodart E, Dramaix-Wilmet M, et al. Exercise-induced respiratory symptoms are poor predictors of bronchoconstriction. Pediatr Pulmonol 2005; 39: 301-305.

American Thoracic Society, European Respiratory Society. ATS/ERS recommendations for standardized procedures for the online and offline measurement of exhaled lower respiratory nitric oxide and nasal nitric oxide, 2005. Am J Respir Crit Care Med 2005; 171: 912-930.

Boot JD, de Ridder L, de Kam ML, et al. Comparison of exhaled nitric oxide measurements between NIOX MINO electrochemical and Ecomedics chemiluminescence analyzer. Respir Med 2008; 102: 1667-1671. Pulmonol 2011; 46: 627-631.

McGill C, Malik G, Turner SW. Validation of a hand-held exhaled nitric oxide analyzer for use in children. Pediatr Pulmonol 2006; 41: 1053-1057.

Schiller B, Hammer J, Barben J, et al. Comparability of a hand-held nitric oxide analyser with online and offline chemiluminescence-based nitric oxide measurement. Pediatr Allergy Immunol 2009; 20: 679-685.

Takalo R, Piirilä P, Sovijärvi AR. Repeatability of successive measurements with a portable nitric oxide analyser in patients with suggested or diagnosed asthma. Scand J Clin Lab Invest 2008; 68: 830-832.

Buchvald F, Baraldi E, Carraro S, et al. Measurements of exhaled nitric oxide in healthy subjects age 4 to 17 years. J Allergy Clin Immunol 2005; 115: 1130-1136.

Malmberg LP, Petäys T, Haahtela T, et al. Exhaled nitric oxide in healthy nonatopic school-age children: determinants and height-adjusted reference values. Pediatr Pulmonol 2006; 41: 635-642.

Vijverberg SJ, Koster ES, Koenderman L, et al. Exhaled NO is a poor marker of asthma control in children with a reported use of asthma medication: a pharmacy-based study. Pediatr Allergy Immunol 2012; 23: 529-536.

Malmberg LP, Pelkonen AS, Mattila PS, et al. Exhaled nitric oxide and exercise-induced bronchoconstriction in young wheezy children - interactions with atopy. Pediatr Allergy Immunol 2009; 20: 673-678.

Pijnenburg MW, Hofhuis W, Hop WC, et al. Exhaled nitric oxide predicts asthma relapse in children with clinical asthma remission. Thorax 2005; 60: 215-218. steroid reduction in children. Am J Respir Crit Care Med 2005; 171: 1077-1082.

Visser CA, Brand PL. Does a single measurement of exhaled nitric oxide predict asthma exacerbations? Arch Dis Child 2011; 96: 781-782.

Cabral AL, Vollmer WM, Barbirotto RM, et al. Exhaled nitric oxide as a predictor of exacerbation in children with moderate-to-severe asthma: a prospective, 5-month study. Ann Allergy Asthma Immunol 2009; 103: 206-211.

Pijnenburg MW, Bakker EM, Hop WC, et al. Titrating steroids on exhaled nitric oxide in children with asthma: a randomized controlled trial. Am J Respir Crit Care Med 2005; 172: 831-836.

Fritsch M, Uxa S, Horak F Jr, et al. Exhaled nitric oxide in the management of childhood asthma: a prospective 6-months study. Pediatr Pulmonol 2006; 41: 855-862.

Szefler SJ, Mitchell H, Sorkness CA, et al. Management of asthma based on exhaled nitric oxide in addition to guideline-based treatment for inner-city adolescents and young adults: a randomised controlled trial. Lancet 2008; 372: 1065-1072.

de Jongste JC, Carraro S, Hop WC, et al. Daily telemonitoring of exhaled nitric oxide and symptoms in the treatment of childhood asthma. Am J Respir Crit Care Med 2009; 179: 93-97.

Fuchs O, Latzin P, Thamrin C, et al. Normative data for lung function and exhaled nitric oxide in unsedated healthy infants. Eur Respir J 2011; 37: 1208-1216.

Malmberg LP, Pelkonen AS, Haahtela T, et al. Exhaled nitric oxide rather than lung function distinguishes preschool children with probable asthma. Thorax 2003; 58: 494-499.

Sonnappa S, Bastardo CM, Wade A, et al. Symptom-pattern phenotype and pulmonary function in preschool wheezers. J Allergy Clin Immunol 2010; 126: 519-526.

Baraldi E, Dario C, Ongaro R, et al. Exhaled nitric oxide concentrations during treatment of wheezing exacerbation in infants and young children. Am J Respir Crit Care Med 1999; 159: 1284-1288.

Moeller A, Franklin P, Hall GL, et al. Measuring exhaled breath condensates in infants. Pediatr Pulmonol 2006; 41: $184-187$.

Oh JW, Lee HB, Kim CR, et al. Analysis of induced sputum to examine the effects of inhaled corticosteroid on airway inflammation in children with asthma. Ann Allergy Asthma Immunol 1999; 82: 491-496.

Kaptein AA, Hughes BM, Scharloo M, et al. Illness perceptions about asthma are determinants of outcome. J Asthma 2008; 45: 459-464.

Singer F, Luchsinger I, Inci D, et al. Exhaled nitric oxide in symptomatic children at preschool age predicts later asthma. Allergy 2013; 68: 531-538.

Moeller A, Diefenbacher C, Lehmann A, et al. Exhaled nitric oxide distinguishes between subgroups of preschool children with respiratory symptoms. J Allergy Clin Immunol 2008; 121: 705-709.

Debley JS, Stamey DC, Cochrane ES, et al. Exhaled nitric oxide, lung function, and exacerbations in wheezy infants and toddlers. J Allergy Clin Immunol 2010; 125: 1228-1234.

Chawes BL, Buchvald F, Bischoff AL, et al. Elevated exhaled nitric oxide in high-risk neonates precedes transient early but not persistent wheeze. Am J Respir Crit Care Med 2010; 182: 138-142.

Kotaniemi-Syrjänen A, Malmberg LP, Malmström K, et al. Factors associated with elevated exhaled nitric oxide fraction in infants with recurrent respiratory symptoms. Eur Respir J 2013; 41: 189-194.

8 Moeller A, Lehmann A, Knauer N, et al. Effects of montelukast on subjective and objective outcome measures in preschool asthmatic children. Pediatr Pulmonol 2008; 43: 179-186.

Gibson PG, Grootendor DC, Henry RL, et al. Sputum induction in children. Eur Respir J 2002; 20: Suppl. 37, $44 \mathrm{~s}-46 \mathrm{~s}$.

Fleming L, Wilson N, Regamey N, et al. Use of sputum eosinophil counts to guide management in children with severe asthma. Thorax 2012; 67: 193-198.

1 Lex C, Payne DN, Zacharasiewicz A, et al. Sputum induction in children with difficult asthma: safety, feasibility, and inflammatory cell pattern. Pediatr Pulmonol 2005; 39: 318-324.

2 Li AM, Tsang TW, Lam HS, et al. Predictors for failed dose reduction of inhaled corticosteroids in childhood asthma. Respirology 2008; 13: 400-407. 
133 Lex C, Jenkins G, Wilson NM, et al. Does sputum eosinophilia predict the response to systemic corticosteroids in children with difficult asthma? Pediatr Pulmonol 2007; 42: 298-303

134 Baraldi E, Ghiro L, Piovan V, et al. Safety and success of exhaled breath condensate collection in asthma. Arch Dis Child 2003; 88: 358-360.

135 Thomas PS, Lowe AJ, Samarasinghe P, et al. Exhaled breath condensate in pediatric asthma: promising new advance or pouring cold water on a lot of hot air? A systematic review. Pediatr Pulmonol 2013; 48: 419-442.

136 Sinha A, Krishnan V, Sethi T, et al. Metabolomic signatures in nuclear magnetic resonance spectra of exhaled breath condensate identify asthma. Eur Respir J 2012; 39: 500-502.

137 Horváth I, Hunt J, Barnes PJ, et al. Exhaled breath condensate: methodological recommendations and unresolved questions. Eur Respir J 2005; 26: 523-548.

138 van de Kant KD, Klaassen EM, Jöbsis Q, et al. Wheezing in preschool children is associated with increased levels of cytokines/chemokines in exhaled breath condensate. J Allergy Clin Immunol 2010; 126: 669-671.

139 von Jagwitz M, Pessler F, Akmatov M, et al. Reduced breath condensate $\mathrm{pH}$ in asymptomatic children with prior wheezing as a risk factor for asthma. J Allergy Clin Immunol 2011; 128: 50-55.

140 Rosias PP, Robroeks CM, van de Kant KD, et al. Feasibility of a new method to collect exhaled breath condensate in pre-school children. Pediatr Allergy Immunol 2010; 21: e235-e244.

141 Zanconato S, Carraro S, Corradi M, et al. Leukotrienes and 8-isoprostane in exhaled breath condensate of children with stable and unstable asthma. J Allergy Clin Immunol 2004; 113: 257-263.

142 Trischler J, Merkel N, Konitzer S, et al. Fractionated breath condensate sampling: $\mathrm{H}_{2} \mathrm{O}_{2}$ concentrations of the alveolar fraction may be related to asthma control in children. Respir Res 2012; 13: 14.

143 Robroeks CM, van de Kant KD, Jöbsis Q, et al. Exhaled nitric oxide and biomarkers in exhaled breath condensate indicate the presence, severity and control of childhood asthma. Clin Exp Allergy 2007; 37: 1303-1311.

144 Kostikas K, Papaioannou AI, Tanou K, et al. Exhaled NO and exhaled breath condensate pH in the evaluation of asthma control. Respir Med 2011; 105: 526-532.

145 Bateman ED, Hurd SS, Barnes PJ, et al. Global strategy for asthma management and prevention: GINA executive summary. Eur Respir J 2008; 31: 143-178.

146 Kostikas K, Papatheodorou G, Ganas K, et al. pH in expired breath condensate of patients with inflammatory airway diseases. Am J Respir Crit Care Med 2002; 165: 1364-1370.

147 Hunt JF, Fang K, Malik R, et al. Endogenous airway acidification. Implications for asthma pathophysiology. Am J Respir Crit Care Med 2000; 161: 694-699. 